\title{
Variáveis no Ensino de Discriminação para Bebês ${ }^{1}$
}

\author{
Maria Stella C. de Alcântara Gil ${ }^{2}$ \\ Thais Porlan de Oliveira \\ Naiara Minto de Sousa \\ Danilo A. de Melo Faleiros \\ Universidade Federal de São Carlos
}

\begin{abstract}
RESUMO - A investigação das condições necessárias para aprendizagem de discriminações condicionais por bebês é um desafio devido às dificuldades relacionadas à manutenção de crianças pequenas em situações experimentais. O objetivo foi ensinar tarefas de pareamento de identidade para um bebê de 12 meses em um experimento conduzido na sala de uma creche. Brinquedos utilizados como estímulos eram expostos em um aparato constituído por três janelas recortadas em uma caixa diante das quais se sentava um experimentador e o bebê. As tentativas iniciavam-se com a abertura das janelas e exposição dos estímulos: no caso da seleção do estímulo definido como S+, o bebê podia pegá-lo e brincar, no caso da seleção do Sas janelas eram fechadas até a tentativa seguinte. Na etapa de pareamento com o modelo, um estímulo idêntico a um dos estímulos comparação era apresentado primeiramente na janela central do aparato. Análises continuadas do desempenho do participante visaram a manipulação de variáveis em vigor para manutenção do bebê na situação e para realização das tarefas propostas.. A discussão relaciona qualidade do desempenho com o controle exercido por variáveis como contato social com experimentador, alterações na duração das tarefas e variedade de estímulos.
\end{abstract}

Palavras-chave: discriminação; pareamento com o modelo; bebês.

\section{Variables in Teaching of Infants Discrimination}

\begin{abstract}
The investigation of the conditions necessary for infants to learn conditional discrimination is a challenge due to the difficulties related to maintaining small children in experimental conditions. The objective was to teach matching identity tasks to a 12-month-old infant in a experimenter organized in a room at a daycare center. Toys used as stimuli were displayed in an apparatus consisting of three windows cutout in a box, in front of which sat an experimenter with the infant. The trials began with the opening of the windows and the display of stimuli: in the case of the selection of the stimulus defined as S+, the infant could take the toy and play, in the case of the selection of S- the windows were closed until the following trial. In the matching phase with the model, a stimulus identical to one of the comparison stimuli was first presented in the center window of the apparatus. Constant analyses of the participant's performance were carried out to manipulate the variables in force to maintain the infant in the experimental situation and to perform the proposed tasks. The discussion relates the quality of performance to the control exercised by variables such as social contact with the experimenter, alterations in the duration of tasks and variety of stimuli.
\end{abstract}

Key words: discrimination; matching to model; infants.

Os trabalhos que investigaram a formação de relações condicionais entre estímulos com a participação de crianças pequenas utilizaram, em geral, procedimentos transpostos de pesquisas realizadas com outras populações. Do estudo realizado por Jordan, Pilgrim e Galizio (2001) participaram crianças com idades entre 2 e 4 anos. Elas foram submetidas a procedimentos de reforçamento diferencial e pareamento com o modelo, seguidos de

1 Este trabalho recebeu apoio financeiro de CNPq e Fapesp. Parte do trabalho foi apresentada no XIII Encontro da Associação de Psicoterapia e Medicina Comportamental/II Encontro Internacional da Associação de Análise de Comportamento, realizado em Campinas - SP, em setembro de 2004. Agradecemos à instituição "Creche Nosso Lar", de São Carlos, SP e a contribuição dos professores Deisy das Graças de Souza e Júlio C. Coelho de Rose.

2 Endereço: Rua Episcopal, no 2474, ap. 141A. São Carlos, SP, Brasil 13560-049.E-mail: mscagil@power.ufscar.br testes para verificação da formação de relações de equivalência. Empregaram estímulos visuais que poderiam ser familiares ou não aos participantes, apresentados em um monitor. Os resultados indicaram, segundo os autores, a eficácia dos procedimentos empregados para verificação de equivalência de estímulos. O estudo, entretanto, contou com um número pequeno de crianças com idade próxima dos 2 anos e os resultados de aprendizagem foram mais consistentes para as crianças mais velhas.

A insistência em enfrentar o desafio de se estudar a emergência de relações condicionais na população de crianças pequenas decorre, em grande parte, da compreensão que algumas capacidades precursoras da habilidade de classificar eventos ou coisas, segundo propriedades comuns, são produto da formação de discriminações complexas entre estímulos que podem se tornar equivalentes entre si (McIlvane, 1992; McIlvane, Dube, Kledaras, Iennaco \& Stoddard, 1990; Saunders \& Spradlin, 1989). 
A questão subjacente é: definir as condições necessárias e suficientes para a formação de relações de equivalência e elaborar metodologia apropriada à investigação do comportamento de crianças pequenas. Sobretudo daquelas que se encontram no período da emergência do comportamento simbólico, tal como ocorrido nas pesquisas com deficientes cujos desempenhos se encontram em níveis considerados iniciais de desenvolvimento (De Rose, 2000; Wilkinson \& McIlvane, 2001).

$\mathrm{Na}$ busca de procedimentos apropriados para ensino de deficientes, a discriminação simples é considerada um passo inicial para definição de condições experimentais para produzir aprendizagem de discriminações condicionais. $\mathrm{O}$ treino de discriminações simples estabelece a definição do estímulo reforçador, a resposta topográfica requerida do participante e a contingência de reforçamento em operação (Dube, 1996; McIlvane, \& cols., 1990; McIlvane, Serna, Dube \& Stromer, 2000). No caso dos estudos com bebês, a etapa de ensino de discriminações simples pode ser considerada primordial por dois conjuntos de razões: 1) porque é a base para aprendizagem de discriminações complexas; 2) porque é a primeira condição para o aprimoramento metodológico dos estudos experimentais com bebês.

Após o treino de discriminações simples entre estímulos, o procedimento de escolha de acordo com o modelo é instrumento usualmente adotado para identificação da emergência de repertórios de discriminação condicional empregados com diversas populações (Dube \& Serna, 1998). O sucesso na adaptação do procedimento de escolha de acordo com o modelo para a realização de estudos com bebês implica a definição de variáveis de controle eficazes para manutenção de bebês em atividades em ambientes experimentais e o investimento em procedimentos que permitam o estudo dos parâmetros da aprendizagem de discriminações simples e condicionais (de Rose, 2000; O’Donnell \& Saunders, 2003; Wilkinson \& McIlvane, 2001).

Independentemente dos entraves para a investigação dos precursores do comportamento simbólico em crianças pequenas, a dificuldade na realização de estudos experimentais com bebês foi descrita em diversos trabalhos. Dentre eles se destacam os estudos de Long, Hammack, May e Campbell (1958), Simmons e Lipsitt (1961), Kagan (1981) e Weisberg e Rovee-Collier (1998) que discutiram e sugeriram alternativas para a quase impossibilidade de se manter bebês em atividade nos ambientes experimentais.

Com o objetivo de investigar variáveis presentes no ensino de tarefas de discriminação simples e pareamento de identidade para um bebê de 24 meses, Gil e Oliveira (2003) organizaram uma situação experimental na creche freqüentada pelo bebê. O aparato construído, as respostas requeridas do bebê e os estímulos especialmente confeccionados para exercerem as funções de estímulos discriminativos e estímulos reforçadores visavam oferecer uma atividade atraente. Procedimentos de discriminação e reversão de discriminação foram seguidos de procedimentos de escolha de acordo com modelo. Os resultados mostraram que diante de um estímulo modelo o bebê emitia respostas sistemáticas de escolha do estímulo- comparação idêntico. A análise permitiu a identificação de relações refinadas entre as respostas do bebê e outros estímulos presentes no ambiente diferentes dos estímulos experimentais.

O caráter flexível da relação entre os controles em vigor na situação e o desempenho de bebês foi descrito no estudo de Oliveira (2003), realizado com outros três participantes, cujas idades variaram entre 16 e 22 meses, submetidos a um procedimento também flexível. Os resultados obtidos sustentam a realização de novas pesquisas com bebês, sobretudo no refinamento do controle experimental.

O objetivo do presente trabalho foi identificar e manipular variáveis relacionadas a 1) manutenção de um bebê na condição experimental proposta e 2) otimizar a aprendizagem de tarefas de discriminações simples e pareamento de identidade.

Alcançar análises apuradas das variáveis em vigor no controle do comportamento dos pequenos em tarefas de discriminação contribuirá para o avanço nas investigações sobre formação de discriminações complexas e auxiliará o desenvolvimento de metodologia para estudos experimentais com bebês. Estudos com bebês menores de 18 meses também se configuram como fundamental para produção de tecnologia de ensino para populações com alguma dificuldade em aprender.

\section{Método}

\section{Participante}

Um bebê com 12 meses de idade no início da coleta, freqüentador do berçário de uma creche da cidade de São Carlos - SP. A avaliação do desenvolvimento do participante foi feita com a aplicação do Teste de Triagem Denver II (Frankenburg, Dodds, Archer e Bresnick, 1990). Foi utilizada a versão adaptada para o português pela Universidade Federal de São Paulo (1999), sem qualquer detecção de "cuidado" ou "atraso" no desenvolvimento. O trabalho foi submetido e aprovado pelo Conselho de Ética da UFSCar, sob o protocolo $N^{\circ} 043 / 03$, segundo a Resolução CNS 196/1996.

Ambiente experimental e material - As sessões experimentais foram realizadas em uma sala da própria creche na qual foi instalado um aparato adaptado daqueles empregados por McIlvane e Stoddard (1981) e Gil e Oliveira (2003).

$\mathrm{O}$ aparato foi construído com uma caixa medindo $(0,80$ $\mathrm{x} 0,56 \mathrm{x} 0,80 \mathrm{~m})$, na qual foram recortadas três janelas paralelas, cada uma medindo 0,20 x 0,30m. Diante das janelas, a uma distância aproximada de $0,60 \mathrm{~m}$, sentavase o bebê e um experimentador. O lado oposto às janelas era aberto para permitir o manejo dos estímulos e do aparato por experimentadores fora do campo visual do bebê. Cada uma das janelas possuía trilhos de alumínio afixados nas laterais que permitiam o deslizamento de placas de acrílico transparente e de placas opacas. Os experimentadores situados atrás do aparato operavam um sistema independente de abertura e fechamento de cada 
uma das janelas. As placas de acrílico permitiam a visualização dos estímulos nas janelas e impediam o acesso ao interior da caixa. As placas opacas, no mesmo material da caixa, vedavam totalmente as janelas. Uma cortina, em tecido neutro, da largura da sala $(2 \mathrm{~m})$, separava o espaço destinado ao bebê e ao adulto que o acompanhava do espaço reservado ao manejo dos estímulos e do aparato. No centro da cortina havia um vão recortado através do qual estavam expostas as janelas do aparato. A Figura 1 apresenta o diagrama do ambiente experimental.

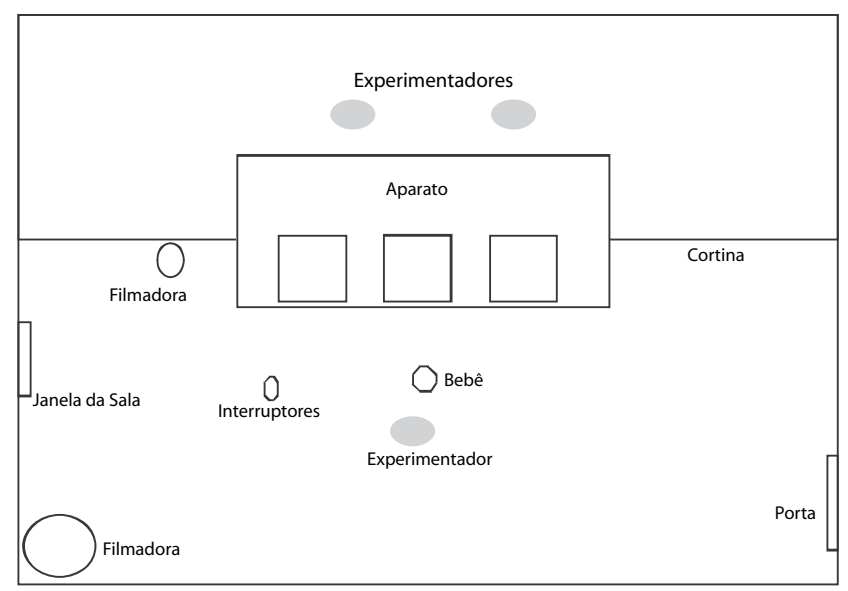

Figura 1. Esquema do ambiente experimental.

Uma câmera digital ficava embutida na cortina e focalizava o rosto do bebê. Uma câmera SVHS permanecia fixa e voltada para o aparato com o foco nas janelas. Foi utilizado sinalizador com duas lâmpadas e dois interruptores para indicar as respostas de seleção corretas e incorretas do participante. O sinalizador com as lâmpadas eram visíveis apenas para o experimentador que operava as janelas do aparato. Cada um dos interruptores e as respectivas lâmpadas foram designados como sinalizador de escolha correta ou incorreta. $\mathrm{O}$ experimentador que permanecia com o bebê acionava um dos interruptores a cada escolha do bebê.

Estímulos - Diversos "bichinhos" foram selecionados de acordo com a faixa etária do bebê e os objetivos do estudo para exercerem as funções de estímulo discriminativo, comparação, amostra e reforçador. Foram classificados segundo o material com o qual foram confeccionados: de sucata, de tecido, de plástico inflável ou de pelúcia. Todos os brinquedos proporcionavam, além da estimulação visual e tátil, a possibilidade de que o manuseio pelo bebê produzisse estimulação sonora e movimento. Na Tabela 1 estão descritas as classes de bichinhos que fizeram parte do estudo e o tipo de estimulação sonora e visual produzida pelo seu manuseio.

\section{Procedimentos}

A coleta de dados foi precedida por um período de familiarização no qual os pesquisadores participaram da rotina do berçário e brincavam livremente com todos os bebês presentes. A coleta de dados ocorreu ao longo de 14 semanas, com participação do bebê em três sessões por semana, aproximadamente.

Tendo em vista os objetivos da pesquisa, é importante ressaltar o caráter flexível e individualizado das variáveis empregadas no estudo: apesar da regularidade quanto aos procedimentos básicos empregados, a análise da prevalência de controle indesejável de outros aspectos do ambiente sobre as respostas do participante resultou em mudanças constantes no arranjo ambiental proposto ao bebê, conforme será descrito no item "variáveis modificadas".

As variáveis referentes às características dos procedimentos de treino (duração das sessões, intervalos entre tentativas e número de tentativas por sessão) foram inicialmente definidas com base nas variáveis descritas por Gil e Oliveira (2003). Cada sessão teve duração média de oito minutos e a duração dos intervalos entre tentativas variou entre 10 e 15 segundos. O número de tentativas por sessão variou entre cinco e 12, dependendo do desempenho

Tabela 1. Brinquedos utilizados como estímulos.

\begin{tabular}{|c|c|c|}
\hline BICHOS & MATERIAL & CARACTERÍSTICAS \\
\hline Porcos & $\begin{array}{l}\text { Tecido liso ou } \\
\text { estampado }\end{array}$ & $\begin{array}{l}\text { Confeccionados com } 4 \text { padronagens de tecido diferentes: duas cores } \\
\text { lisas e duas estampadas. Os bichinhos foram pareados em dois grupos de } \\
\text { estímulos: amarelo e bolinha ou azul e listrado. Cada brinquedo possuía } \\
\text { um sistema de som e luzes que, ao ser acionado pela experimentadora, } \\
\text { iniciava o toque de músicas infantis juntamente com o piscar de luzinhas } \\
\text { (localizadas nas laterais do corpo) por aproximadamente } 6 \text { segundos }\end{array}$ \\
\hline $\begin{array}{l}\text { Peixe,cachorro, coelho,pato } \\
\text { sapo, panda, galinha }\end{array}$ & Plástico - Infláveis & $\begin{array}{l}\text { Tinham pequenos guizos presos por elástico ao pescoço e produziam som } \\
\text { (tipo buzina) ao serem apertados }\end{array}$ \\
\hline Cavalo,sapo & Pelúcia - molas & $\begin{array}{l}\text { Bichos cuja cabeça era presa a uma mola flexível que constituía o corpo do } \\
\text { animal. Em uma ponta da mola havia a cabeça e na outra os pés do bicho } \\
\text { Produziam sons de animais (cavalo e sapo) ao serem pressionados contra } \\
\text { algum tipo de superfície (por ex. batê-los no chão) }\end{array}$ \\
\hline Coelho,vaca & Pelúcia & Tinham pequenos guizos presos por elástico no pescoço \\
\hline Garrafinhas & sucata & $\begin{array}{l}\text { Eram lacradas e cheias de um líquido colorido que poderia ser de duas } \\
\text { cores. Foram pareadas em dois grupos de estímulos dependendo da cor do } \\
\text { líquido: azul ou rosa Tinham guizos presos por elástico próximo da tampa. }\end{array}$ \\
\hline
\end{tabular}


do bebê. Independente de quaisquer critérios estabelecidos, a sessão era interrompida sempre que o bebê apresentasse sinais de cansaço ou irritabilidade.

\section{Procedimentos básicos}

Discriminação simples e reversão - Nesta etapa foram utilizadas apenas as duas janelas laterais do aparato; a janela central do aparato permanecia sempre vedada pela placa opaca. Cada tentativa tinha início com a abertura simultânea das placas opacas e com a exposição dos bichinhos em cada uma das janelas laterais do aparato. A pesquisadora, então, perguntava ao bebê: "qual você quer?", ou dizia: "pegue o que você quer".

O bichinho exposto na janela tocada pelo bebê, na primeira tentativa, era sempre designado $\mathrm{S}+$. Ao tocar a janela, a placa de acrílico se levantava e o bebê tinha acesso ao brinquedo. Ele podia, então, brincar com o bichinho por aproximadamente 12 segundos e, após este período, a pesquisadora retirava o brinquedo delicadamente das mãos do bebê e o empurrava para debaixo da cortina.

A partir da segunda tentativa, ao tocar a janela que expunha o bichinho que fora designado $\mathrm{S}+$, o bebê tinha acesso ao brinquedo. Ao tocar a janela que expunha o S-, as duas janelas eram vedadas até o início da próxima tentativa.

O critério de aquisição de discriminação, que determinava a passagem para a etapa seguinte do procedimento, foi de quatro escolhas consecutivas do estímulo designado como $\mathrm{S}+$. Ao atingir o critério para discriminação simples entre dois estímulos, iniciava-se o procedimento de reversão das funções dos estímulos, ou seja, o estímulo anteriormente designado $S+$ passava a exercer função de S- e vice-versa, até que o critério fosse novamente atingido pelo participante.

Pareamento de identidade - A etapa seguinte ao treino de discriminação simples e reversão consistiu do procedimento de pareamento com um estímulo modelo fisicamente similar a um estímulo comparação.

A diferença da etapa de treino de discriminação simples foi o início das tentativas com a apresentação, na janela central do aparato, de um estímulo modelo:um bichinho idêntico a um dos estímulos comparação. Após a abertura da placa opaca e da exposição do brinquedo na janela central, a experimentadora emitia instrução verbal oral ("olha lá!"). O bebê deveria emitir uma resposta de observação em seguida da qual as janelas laterais eram abertas e os estímulos-comparação expostos. Neste estudo respostas de observação foram definidas como olhar, por no mínimo 6 segundos, para o estímulo ou apontar ou aproximar-se da janela.

Com a abertura das janelas laterais ocorria concomitantemente o fechamento da janela central - procedimento denominado "pareamento com modelo com atraso" - e a pesquisadora perguntava ao bebê: "qual você quer?" ou dizia: "pegue qual você quer". Quando bebê tocava a janela que expunha o estímulo comparação idêntico ao modelo, a janela se abria e o bebê tinha acesso ao brinquedo e podia brincar durante cerca de 12 segundos; se o bebê tocasse a janela que expunha o $\mathrm{S}$ - as janelas eram vedadas. O procedimento de pareamento de identidade foi dividido em três etapas, de acordo com a introdução gradual da apresentação do estímulo modelo:
- Pareamento de Identidade 1 (PI1) - Na primeira etapa, uma sessão era constituída por dois blocos de quatro tentativas cada, com a utilização de dois estímulos comparação e de um estímulo modelo em cada bloco. Nas primeiras quatro tentativas um estímulo era o modelo e, nas quatro tentativas seguintes da mesma sessão, o outro estímulo era apresentado como modelo. Após alcançar o critério de aprendizagem de pareamento de identidade com um par de estímulos, o participante passava ao treino seguinte.

- Pareamento de Identidade 2 (PI2) - Nesta etapa uma sessão era constituída por quatro blocos de duas tentativas cada, com dois estímulos-comparação e de um estímulomodelo em cada bloco. Nas duas primeiras tentativas do primeiro bloco, o estímulo A era o modelo, nas duas tentativas seguintes o estímulo B era modelo; no terceiro bloco o estímulo A voltava a ser apresentado como modelo e no quarto bloco o estímulo B era novamente apresentado como modelo nas últimas duas tentativas.

- Pareamento de Identidade Misto (PI MISTO) - A última etapa do procedimento foi o treino de pareamento de identidade com a variação da função dos estímulos-comparação a cada tentativa. O treino foi realizado com dois estímuloscomparação e mudança randômica do estímulo-modelo, a cada tentativa.

\section{Variáveis modificadas}

Algumas variáveis de procedimento foram modificadas em decorrência da análise das contingências entre as respostas do bebê e diversos aspectos presentes na situação experimental que controlavam a ocorrência de comportamentos do participante sob controle dos estímulos não programados, resultando em baixa freqüência de escolhas corretas.

Procedeu-se à observação sistemática das videogravações das sessões. Em um protocolo de transcrição foram registrados os eventos ambientais relacionados ou não às variáveis experimentais antecedentes e subseqüentes às respostas do bebê, que poderiam ser tanto dirigidas ao aparato ou estímulos quanto aquelas dirigidas a outros aspectos do ambiente e as respostas do experimentador que acompanhava o bebê. Dois aspectos relevantes foram identificados e manipulados: 1) os estímulos efetivos na manutenção do bebê na sala experimental e 2) os estímulos efetivos para a realização das tarefas de discriminação.

\section{Estímulos efetivos na manutenção do bebê na sala experimental}

\section{O cantinho dos brinquedos}

Os estímulos efetivos (reforçadores) na manutenção do bebê na sala experimental foram introduzidos após a décima sessão. Consistiram na brincadeira livre, por cinco minutos, imediatamente após as tentativas de treino. O participante era dirigido pelo experimentador ao cantinho dos brinquedos, na própria sala experimental, onde podia brincar com brinquedos diferentes daqueles utilizados na aprendizagem de discriminação.

As duas condições experimentais, anterior e posterior à introdução da brincadeira livre, foram classificadas como: 
Condição A: sessões de 1 até 10 - imediatamente após a realização da sessão o bebê era levado de volta ao berçário.

Condição B: da sessão 11 em diante - após a realização da sessão, o experimentador orientava o bebê para o cantinho dos brinquedos onde permanecia por cinco minutos e então era levado de volta ao berçário.

\section{A brincadeira bebê-brinquedo-experimentador}

Considerando os estímulos efetivos (reforçadores) em relação à realização das tarefas de discriminação, nas cinco sessões finais $(19,20,21,22$ e 23) foi introduzida a variável brincadeira do experimentador com o bebê e o brinquedo $\mathrm{S}+$ correto. Nas cinco sessões, todas as vezes que o participante selecionava o estímulo correto, brincava com o bichinho e com o experimentador por alguns segundos. "Brincar com" foi definido como a interação do adulto com o bebê contingente aos comportamentos do bebê relacionados ao brinquedo (por exemplo, olhar para o bichinho e para o bebê, sorrir, acionar luzes e sons do bichinho e mostrar para o bebê). Neste período, o adulto não emitia nenhum tipo de vocalização direcionada ao bebê.

As duas condições, anterior e posterior à introdução da brincadeira conjunta, foram classificadas como:

Condição $C$ : após selecionar o estímulo correto na tarefa, o bebê permanece com o brinquedo durante alguns segundos, sem a interferência do adulto;

Condição D: após selecionar o estímulo correto na tarefa, o bebê brinca com o bichinho e o adulto brinca em silêncio com o bebê e o brinquedo.

\section{Descrição dos procedimentos realizados}

A seqüência de procedimentos realizados, as sessões, os estímulos utilizados e as variáveis manipuladas ao longo de todo estudo estão sumarizados na Tabela 2.

Tabela 2. Procedimentos realizados com o participante durante todo o estudo.

\begin{tabular}{llll}
\hline Sessões & Treinos & Variáveis Presentes* & Estímulos \\
\hline $1,2,3,4$ & DS1, RE1 & Condição A+C & tecido (porcos) \\
$5,6,7,8$ & PI1 & Condição A+C & tecido (porcos) \\
9,10 & DS2 & Condição A+C & infláveis (peixe/coelho) \\
11 & DS2/3 & Condição B+C & infláveis (peixe/cachorro) \\
12 & PI1 & Condição B+C & infláveis (sapo/cachorro) \\
13,14 & DS3 & Condição B+C & infláveis (sapo/peixe) \\
15 & DS4 & Condição B+C & infláveis (panda/galinha) \\
16 & PI1 & Condição B+C & pelúcia Cavalo/sapo (molas) \\
17,18 & PI2 & Condição B+C & pelúcia cavalo/sapo (molas) \\
19,20 & PI MISTO & Condição B+D & pelúcia (coelho verde/vaca) \\
21 & PI MISTO & Condição B+D & pelúcia Cavalo/sapo (molas) \\
22,23 & PI MISTO & Condição B+D & \\
\hline
\end{tabular}

* Nota - As siglas representam o delineamento experimental de cada um dos seguintes procedimentos:

DS - Discriminação Simples; RE - Reversão da Discriminação; PI1 - Pareamento de identidade com 2 blocos de 4 tentativas, cada bloco com um dos estímulos como modelo; PI2 - Pareamento de identidade com 4 blocos de 2 tentativas, cada bloco com um dos estímulos como modelo; PI MISTO - Pareamento de Identidade variando o modelo randomicamente a cada tentativa.

Variáveis presentes: Condição A - bebê levado ao berçário imediatamente após a sessão; Condição B - introdução do cantinho dos brinquedos; Condição C

- bebê brinca sozinho com estímulo ; Condição D - introdução da brincadeira conjunta com o experimentador.

1 :indica mudança dos estímulos durante a sessão.

Tabela 3. Definição das classes de respostas do bebê.

\begin{tabular}{lll}
\hline Classes de respostas & Características & Descrição topográfica \\
\hline Acerto, erro & $\begin{array}{l}\text { Respostas de escolha do bebê direcionadas aos } \\
\text { estímulos de interesse (brinquedos) }\end{array}$ & $\begin{array}{l}\text { Olhar em direção a uma das janelas do aparato, no período de até 15 } \\
\text { segundos após a instrução da experimentadora, ocorrendo conjuntamente } \\
\text { com uma ou mais respostas de escolha do bebê, tais como: aproximar-se } \\
\text { da janela, tocá-la, apontar, por exemplo }\end{array}$ \\
\hline Não escolha & $\begin{array}{l}\text { Respostas de não escolha do bebê aos estímulos } \\
\text { de interesse (brinquedos) }\end{array}$ & $\begin{array}{l}\text { Bebê fica com o tronco e a cabeça voltados para as janelas do aparato } \\
\text { e permanece silencioso e imóvel por no mínimo 15 segundos após } \\
\text { instrução da experimentadora }\end{array}$ \\
\hline Outros comportamentos & $\begin{array}{l}\text { Ações do bebê direcionadas a outros aspectos do } \\
\text { ambiente que não os brinquedos-estímulo }\end{array}$ & $\begin{array}{l}\text { Quaisquer ações do bebê direcionadas a outros aspectos do ambiente, } \\
\text { incluindo ambiente físico e interação com experimentadora, tais como: } \\
\text { levantar-se e andar pela sala, olhar para partes do seu próprio corpo, } \\
\text { virar-se para a experimentadora etc. }\end{array}$ \\
\hline Vocalizações & $\begin{array}{l}\text { Resposta oral emitida durante a exposição dos } \\
\text { estímulos ou no intervalo entre tentativas }\end{array}$ & $\begin{array}{l}\text { Vocalizações ocorrendo ou não conjuntamente com ações do tipo } \\
\text { apontar para as janelas. Constituía-se de sons expressivos, tais como “ah, } \\
\text { ah, lá!” }\end{array}$ \\
\hline
\end{tabular}




\section{Tratamento e análise dos dados}

Os videoteipes de cada sessão foram examinados por dois experimentadores independentes e foram selecionadas 10 sessões para transcrição e análise detalhada das variáveis de controle relacionadas às respostas de escolha correta, erros, não-escolha e outras respostas do participante. A definição das respostas do bebê para análise dos resultados é apresentada na Tabela 3. A seleção das sessões a serem transcritas considerou: a variabilidade de resposta do bebê; a freqüência de respostas corretas e incorretas e as mudanças no procedimento de treino (variação dos estímulos e introdução das condições B e D descritas). A análise das sessões selecionadas foi realizada pelo registro da freqüência de ocorrência das respostas do bebê para diferentes aspectos do ambiente e suas conseqüências. As classes de eventos foram codificadas em um protocolo que descrevia: a natureza do estímulo antecedente, se estímulos programados ou outros estímulos presentes na situação; as características topográficas das respostas dos bebês em direção aos estímulos antecedentes tais como deslocamentos, direção do olhar, manuseio etc.; as classes de respostas decorrentes (acertos, erros, não-escolhas e outros comportamentos); as variáveis subseqüentes às respostas.

\section{Resultados}

Os resultados apresentados referem-se às sessões selecionadas para análise das variáveis em vigor.

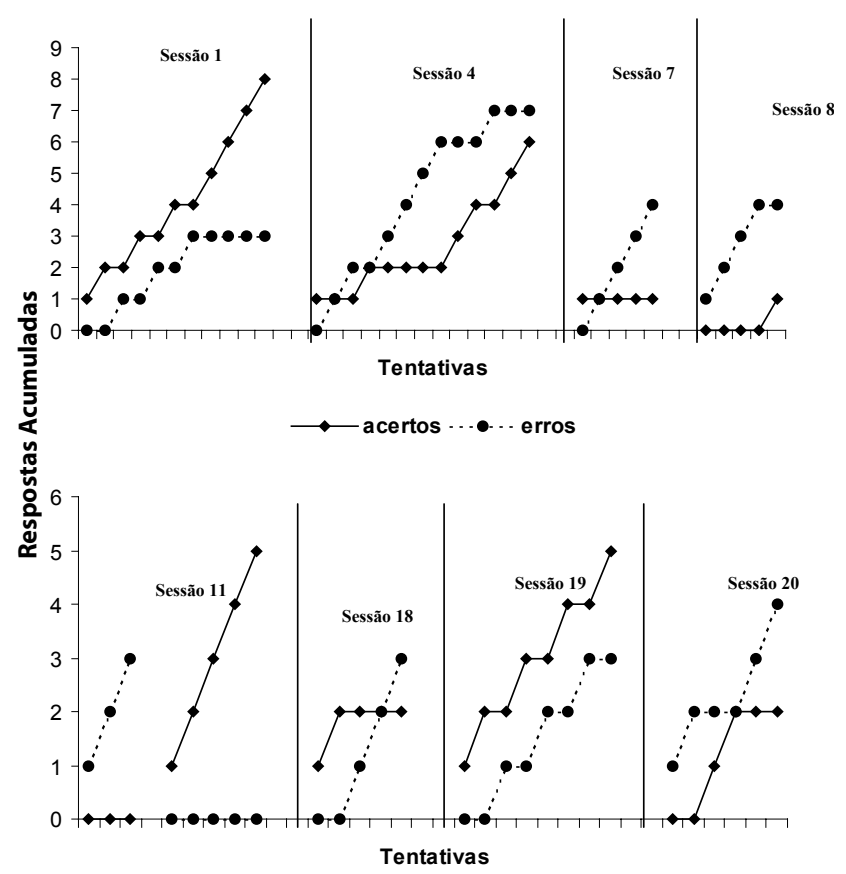

Figura 2. Frequiència de acertos e erros ao longo das tentativas do bebê nas diferentes condições experimentais. Nota - Sessões 1, 4, 7 e 8 condição A+C; sessões 11 e 18 condição $B+C$; sessões 19 e 20 condição $B+D$. Para efeito de análise, as respostas de erro incluem as respostas de não escolha.
A Figura 2 mostra as respostas de acertos e erros do bebê ao longo das tentativas em todas as sessões analisadas. Para efeito de análise, nesta figura as respostas de erro incluíram as respostas de não-escolha do bebê. Nas sessões iniciais $(1,4,7$, e 8$)$, o bebê era levado de volta ao berçário logo após a sessão e brincava sozinho com o bichinho sempre que emitia respostas corretas (condição experimental $A+C$ ). Nas Sessões 11 e 18 o participante também brincava sozinho com o bichinho sempre que emitia respostas corretas, mas logo após a sessão, o experimentador orientava o bebê para o cantinho dos brinquedos (condição B+C). Nas Sessões 19 e 20, além do encaminhamento do bebê ao cantinho dos brinquedos após a sessão, foi introduzida a variável brincar com o adulto e com o bichinho quando o participante emitia respostas corretas (condição B+D).

No início da primeira sessão ocorreram respostas alternadas de acerto e erro e, ao final da sessão, o bebê emitiu respostas consecutivas de escolha do $\mathrm{S}+\mathrm{e}$ alcançou o critério de aprendizagem, o que sugere a vigência de controle pelos brinquedos programados. Na quarta sessão, os erros ocorreram com alta freqüência na maioria das tentativas e ao final da sessão, ocorreram duas respostas corretas, um erro e duas respostas corretas.

Nas Sessões 7 e 8, os dados mostraram a quase ausência de respostas corretas e a diminuição do tempo de permanência do participante na situação experimental. $\mathrm{O}$ desempenho do participante nestas sessões sugere a queda do controle exercido pelos brinquedos-estímulo, dada a baixa freqüência de respostas dirigidas aos bichinhos e o número menor de tentativas nas sessões quando comparadas às Sessões 1 e 4. A interrupção das sessões foi justificada pelos claros indícios de cansaço do bebê tais como se levantar, olhar ou andar em direção a porta.

A parte inferior da Figura 2 mostra os resultados referentes às sessões em que mudanças foram introduzidas. As curvas que descrevem o desempenho do bebê nas Sessões 11 e 18 apresentam a freqüência de respostas acumuladas ao se incluir o cantinho dos brinquedos para o qual o bebê era levado logo após o término das tentativas.

Os dados da Sessão 11 mostram que o participante errou as três primeiras tentativas. Para evitar comportamentos indicativos de saciação do bebê, como pode ter ocorrido nas Sessões 7 e 8, realizou-se a mudança dos brinquedosestímulo a partir da quarta tentativa. Pode-se observar nas curvas do desempenho que as respostas do bebê a um dos brinquedos aumentaram com a substituição.

A curva da Sessão 18 mostra a ocorrência de dois acertos consecutivos seguidos por três erros, com o retorno do predomínio de erros. Estes dados sugerem que o valor reforçador dos bichinhos havia decrescido, a despeito da mudança dos brinquedos-estímulo a cada sessão e da introdução do cantinho dos brinquedos ao final das tentativas da sessão.

Os dados das duas últimas sessões (19 e 20) apresentados na Figura 2 mostram respostas ocorridas em sessões nas quais o brincar com o experimentador foi introduzido, contingente às escolhas corretas do participante. Na Sessão 19, os dados indicam alternância de erros e acertos e, por- 


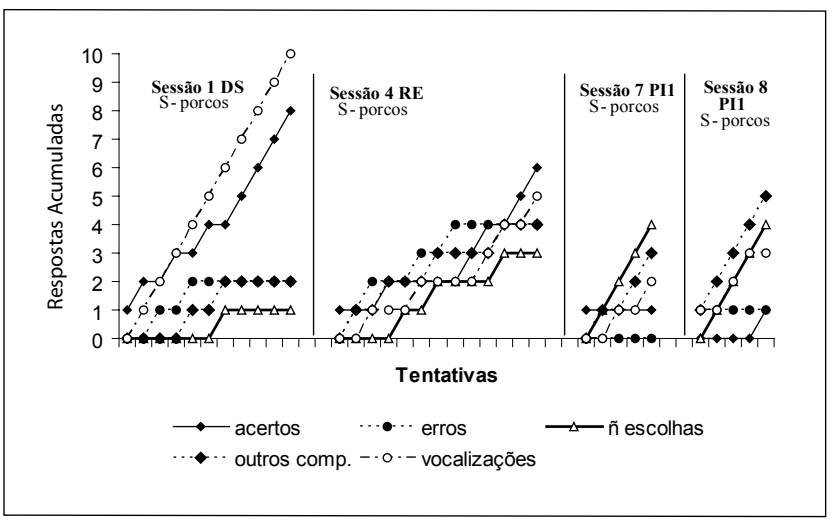

Figura 3. Freqüência de respostas acumuladas ao longo das tentativas do bebê na condição cxperimental $\mathrm{A}+\mathrm{C}$.

Nota: $\mathrm{S}$ = estímulos; $\mathrm{DS}$ = discriminação simples; RE = reversão; PI1, PI2 $=$ pareamento de identidade com mesmo modelo.

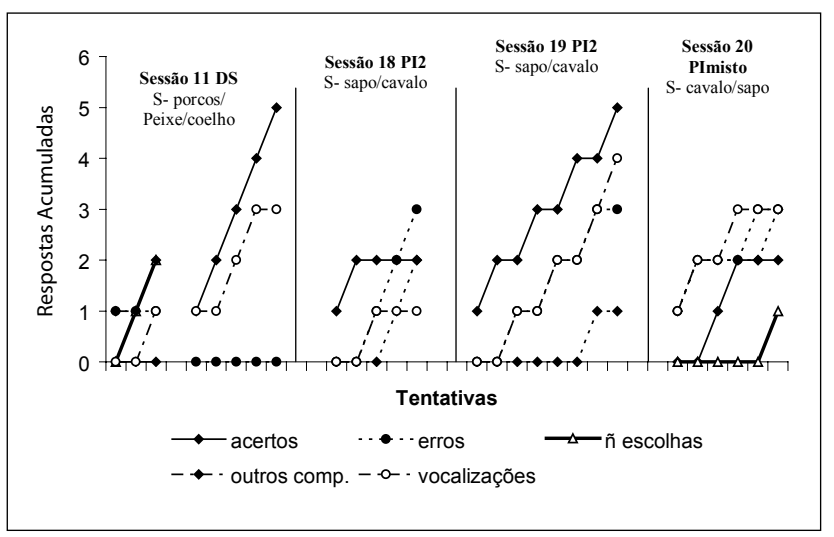

Figura 4. Freqüência de respostas acumuladas ao longo das tentativas do bebê nas condições experimentais B + C (sessões 11 e 18) e B + D (sessões 19 e 20).

Nota: $\mathrm{S}$ = estímulos; DS = discriminação simples; PI1, PI2 = pareamento de identidade com mesmo modelo; PIMISTO = pareamento de identidade alternando o modelo.

tanto, o desempenho do bebê sob controle dos estímulos experimentais. Na Sessão 20 também ocorreu alternância de acertos e erros, porém, os dois erros consecutivos nas últimas tentativas foram acompanhados de sinais de cansaço do participante, o que provocou a interrupção da sessão.

As análises sistemáticas das respostas do bebê aos diferentes aspectos do ambiente ao longo das sessões resultaram na ampliação das classes de desempenho sob análise. Foram consideradas, não apenas as respostas direcionadas aos estímulos experimentais, mas também as respostas classificadas como "outros comportamentos" e "vocalizações". Na Tabela 3 estão definidas as classes de respostas: acerto/erro; não-escolha; outros comportamentos e vocalizações. Para análise das Figuras 3 e 4 é importante notar que as respostas-erro diferem das respostas de não-escolha e que a ocorrência de outros comportamentos poderia ser concomitante aos erros e não-escolhas.

A Figura 3 mostra os dados referentes à situação experimental na qual as mudanças ainda não tinham sido realizadas $(\mathrm{A}+\mathrm{C})$. Foram registradas as classes de respostas: acertos, erros, não-escolhas, outros comporta- mentos e vocalizações. Os procedimentos em vigor nas sessões analisadas foram: discriminação simples, reversão e pareamento de identidade com o mesmo modelo (DS, RE e PI1).

Nas Sessões 1 e 4, respectivamente de discriminação e de reversão da discriminação, observa-se a ocorrência de todas as classes de respostas, o que sugere um controle do comportamento do bebê por vários estímulos presentes na situação. Na primeira sessão, os erros foram dois e o bebê atingiu o critério de aprendizagem ao emitir quatro acertos consecutivos no final da sessão. $\mathrm{Na}$ Sessão 4, o aumento da freqüência de ocorrência de outros comportamentos do bebê mostrou o aumento do controle exercido por outros aspectos do ambiente; nas cinco últimas tentativas não houve ocorrência de respostas ao S-, nem de respostas de escolha do $\mathrm{S}+$.

A análise das classes de respostas do participante nas Sessões 7 e 8 indicou que a diminuição de respostas direcionadas aos estímulos experimentais (acertos e erros) ocorreu concomitantemente ao aumento de respostas de não-escolha e de outros comportamentos. Os experimentadores decidiram, então, introduzir novas mudanças de procedimento.

As mudanças basearam-se na hipótese de que algumas variáveis poderiam influenciar o valor reforçador dos estímulos experimentais: 1) variáveis relacionadas à manutenção do bebê na situação, e 2) variáveis relacionadas ao repertório comportamental exigido pela introdução do procedimento de pareamento de identidade. Para os experimentadores, era imprescindível que a manutenção do bebê na situação fosse assegurada para que o segundo grupo de variáveis pudesse ser investigado.

A Figura 4 expõe os dados referentes às sessões nas quais as variáveis foram modificadas. Na Sessão 11 houve a volta ao procedimento de discriminação simples e o participante emitiu um erro e duas não-escolhas nas tentativas iniciais. Para garantir a permanência do bebê na situação, os bichinhos foram trocados a partir da quarta tentativa. A curva mostra respostas consecutivas de escolha de um dos brinquedos pelo participante e ausência de outros comportamentos ou não-escolhas até o final da sessão.

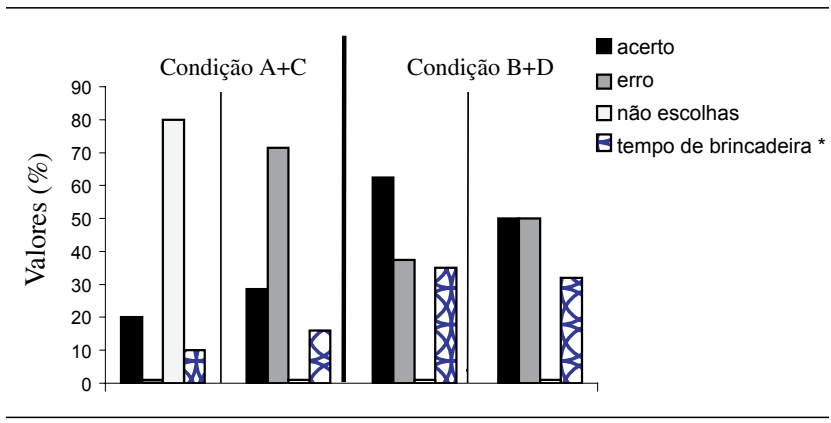

Figura 5. Porcentagem de respostas de acertos, erros e não escolhas emitidas pelo participante e tempo de brincadeira com o estímulo $\mathrm{S}+$ em relação à porcentagem total de tempo em diferentes condições experimentais.

Nota. *Tempo de brincadeira foi calculado como a relação entre duração total da sessão e soma do tempo em que o bebê permaneceu brincando com os estímulos durante a sessão. 
Os dados da Sessão 18 mostram que, apesar da introdução do cantinho da brincadeira ao final das tentativas, o bebê emitiu três respostas consecutivas de erros acompanhados de outros comportamentos, e a sessão foi mais curta, com apenas cinco tentativas. Assim, nas Sessões 19 e 20, outra variável foi manipulada: a introdução do brincar em silêncio do experimentador com o bebê e o S+.

Na Sessão 19, as respostas do participante alternaram-se entre erros e acertos, porém houve baixa freqüência de outros comportamentos e não escolha. As respostas registradas na Sessão 20 foram de alta frequiência de outros comportamentos e uma não-escolha na última tentativa. Este desempenho, conforme será discutido a seguir, pode ser atribuído ao cansaço ou saciação do bebê juntamente com a dificuldade do novo repertório exigido no procedimento de pareamento de identidade misto.

Os resultados apresentados mostraram mudanças no desempenho do participante com a manipulação de variáveis pelo experimentador. A Figura 5 mostra dados comparativos entre as diferentes condições experimentais. Foram calculadas as porcentagens de acertos, erros, não-escolhas e o tempo que o bebê permaneceu brincando com os estímulos durante a sessão em relação à duração total da sessão.

Podemos notar que na condição experimental $\mathrm{A}+\mathrm{C}$ houve alta ocorrência de não-escolhas (Sessão 7) e de erros (Sessão 9). Nas condições em que foram incluídos o cantinho de brincadeira e a brincadeira com o experimentador (Sessões 20 e 21) observou-se baixa porcentagem de não-escolhas, aumento médio no tempo de brincadeira com o S+ e aumento da porcentagem de acerto em relação às condições experimentais anteriores.

\section{Discussão}

Os objetivos do trabalho focalizaram dois aspectos relacionados à investigação de variáveis no ensino de discriminações simples e condicionais para bebês. O primeiro tratou de variáveis de controle que fossem eficazes para a permanência do participante na sala experimental, e o segundo considerou variáveis experimentais relacionadas à realização das tarefas de aprendizagem de discriminação propostas ao bebê.

$\mathrm{O}$ exame dos resultados das sessões realizadas antes e após a manipulação das variáveis mostrou, de um modo geral, o aumento do tempo de permanência e da participação do bebê tanto na realização das tarefas quanto no ambiente experimental. Nas sessões seguintes às modificações introduzidas houve equilíbrio no que se refere ao número de tentativas por sessão e à manutenção das respostas do bebê direcionadas ao aparato, acompanhadas da redução das respostas de não-escolha.

Especificamente quanto à manutenção do participante na sala experimental, a variável modificada foi a introdução de um período de brincadeira livre após o encerramento das tarefas de discriminação (condição B). Na condição que previa o retorno do bebê ao berçário imediatamente após o final do treino (condição A) observou-se a ocorrência de "outros comportamentos" ao final das sessões o que sugeriu um possível caráter aversivo adquirido pela situação, pois o participante levantava-se e andava em direção à porta encerrando a sessão. Obteve-se na condição B a permanência do bebê na sessão acompanhada da redução de repostas direcionadas a outros aspectos do ambiente, diferentes do aparato, principalmente ao final das sessões.

Quanto às variáveis experimentais diretamente relacionadas à realização das tarefas de discriminação pelo bebê, foram relevantes diversas alterações: a definição do menor número de tentativas por sessão; a diminuição do intervalo de tempo entre tentativas e do critério de aprendizagem; algumas características dos estímulos utilizados e dos procedimentos de treino e a introdução da condição D (brincadeira conjunta do experimentador com o bebê após escolha do $\mathrm{S}+$ ).

Em relação ao número de tentativas, e conseqüente duração das sessões, as sessões mais eficazes quanto à participação do bebê tiveram duração máxima de oito minutos, contando com, no máximo, oito tentativas consecutivas e com intervalo médio entre tentativas de 15 segundos. O intervalo médio entre tentativas, de 15 segundos, possibilitava o manejo adequado do aparato. O exame do desempenho do participante indicou que sessões relativamente curtas são mais eficientes na redução da ocorrência de outros comportamentos, o que permite supor o aumento do controle das respostas do bebê pelo aparato e pelos estímulos experimentais. Estudos posteriores deveriam considerar, entretanto, a necessidade de aprimoramento das técnicas de ensino e dos equipamentos para reduzir ainda mais o intervalo entre as tentativas de treino de discriminação.

Quanto ao critério de aprendizagem, no estudo de Oliveira (2003), os quatro participantes alcançaram o critério de quatro escolhas corretas consecutivas. Neste estudo, entretanto, o desempenho do bebê em algumas sessões indicou que talvez seja necessário rever este critério em estudos posteriores. Isto porque, por exemplo, em algumas sessões o participante emitia três respostas corretas e depois uma errada ou demonstrava sinais de cansaço nas últimas tentativas. Há a possibilidade de que o critério a ser empregado deva ser melhor investigado tendo em vista as peculiaridades do repertório dos bebês, como a alta variabilidade de comportamentos e a dificuldade de manutenção do valor reforçador dos estímulos e procedimentos.

A análise continuada não só da relação entre o desempenho do participante e as condições experimentais em vigor, mas também, da relação entre as respostas do bebê e o ambiente circundante resultaram na definição do número de tentativas por sessão; do intervalo entre as tentativas e do critério de aprendizagem. Considerar as classes de resposta "não-escolha" e "outros comportamentos", além das classes acertos e erros, ampliou a possibilidade de aperfeiçoar o controle experimental. Identificar a alta ocorrência de nãoescolhas e de outros comportamentos nas sessões sugeriu o baixo controle exercido pelos brinquedos-estímulo sobre as respostas de escolha do bebê e a conseqüente dificuldade para o ensino das discriminações.

A escolha dos brinquedos e a alteração dos pares de estímulos apresentados para o bebê foram planejadas para aumentar o valor reforçador dos estímulos. Todos os brinquedos selecionados produziam sons e movimento a partir do manuseio pelo bebê. Com o objetivo de maximizar a participação nas tarefas e considerando a alta variabilidade das respostas exploratórias dos bebês, os brinquedos foram substituídos a cada sessão. 
A análise dos resultados permitiu supor, no entanto, que a substituição dos brinquedos a cada sessão pode ter produzido o aumento do número de tentativas até que o participante atingisse o critério de aprendizagem, pois na maior parte das vezes em que houve a troca de estímulos, uma sessão não foi suficiente para o alcance do critério de aprendizagem. Este é mais um aspecto para ser considerado em estudos posteriores: a necessidade de manter a apresentação dos mesmos estímulos visando o aprendizado, e a importância de se preservar o valor reforçador dos estímulos com a troca dos brinquedos antes que o bebê apresente sinais de saciação.

Em relação à busca de procedimentos experimentais eficazes para o ensino de discriminações para bebês, os resultados mostraram que a introdução de treino de discriminações mais complexas geralmente produziu mudança no desempenho do participante. Com o início do treino de pareamento de identidade misto ocorreu alta freqüência de outros comportamentos na sessão. Dois fatores podem ter contribuído para tal: 1) a possível dificuldade da nova tarefa para o repertório do bebê, e 2) a perda do valor reforçador decorrente da alta exposição aos procedimentos.

\section{Considerações Finais}

É importante destacar que as variáveis envolvidas na manutenção do bebê no ambiente experimental e o manejo de variáveis para estabelecer procedimentos eficazes e eficientes para o estudo da aprendizagem de discriminação simples e de discriminação condicional se entrelaçam e, muitas vezes, se confundem em conseqüência do caráter dinâmico da investigação do repertório flexível como é o dos bebês.

Neste trabalho, a possibilidade de distinguir uma condição de outra foi otimizada pela análise descritiva das contingências em vigor nas situações propostas ao bebê. Este instrumento permitiu a definição, o teste e a análise constante das respostas do participante em função das prováveis variáveis de controle antecedentes e subseqüentes. Tal procedimento produziu uma investigação compatível com o caráter dinâmico do comportamento do bebê no sentido de possibilitar aos experimentadores a proposição de novas hipóteses e de teste de outros parâmetros experimentais ao longo de todo o estudo. As decisões estiveram ancoradas nas relações identificadas entre as respostas requeridas do bebê e as condições experimentais que lhe foram oferecidas.

O trabalho mostrou a possibilidade de realização de pesquisas experimentais especialmente planejadas para o ensino de discriminações para bebês. O caminho, contudo, permanece aberto para aprofundar a investigação de problemas relacionados, principalmente, às dificuldades em se conciliar peculiaridades dos comportamentos dos pequenos com demandas decorrentes dos procedimentos para aprendizagem de discriminações. A aprendizagem de discriminações requer a construção de uma história de reforçamento que, em geral, envolve sobreposição de etapas e consome tempo; o desafio está em conformar estas características às dificuldades relacionadas à tolerância e cooperação dos bebês aos ambientes experimentais.

\section{Referências}

De Rose, J. C. C. (2000). Equivalência de estímulos: uma área em busca de um problema. Anais do IX Encontro da Associação Brasileira de Psicoterapia e Medicina Comportamental (pp. 45). Campinas, SP.

Dube, W. V. (1996). Teaching discrimination skills to persons with mental retardation. Em C. Goyos, M. A. Almeida \& D. G. de Souza (Rev.ed.), Temas em Educação Especial, 3 (pp. 96-115). São Carlos: UFSCAR.

Dube, W. V. \& Serna, R. W. (1998). Re-evaluation of a programmed method to teach generalized identity matching to sample. Research in Developmental Disabilities, 19(4), 347-379.

Frankenburg, K. W., Dodds, J., Archer, P. \& Bresnick, B. (1990). Denver II: Technical Manual and Training Manual. Denver: Denver Developmental Manuals Inc.

Gil, M. S. C. A. \& Oliveira, T. P. (2003). Um procedimento de treino de discriminação condicional com bebês. Em M. Z. Brandão \& cols. (Orgs), Sobre Comportamento e Cognição: Clínica, Pesquisa e Aplicação (pp. 469-477). Santo André, SP: ESETec Editores Associados, v.12.

Jordan, C. R., Pilgrim, C. \& Galizio, M. (2001). Conditional discrimination and stimulus equivalence in young children following three different baseline training procedures. Experimental Analysis of Human Behavior Bulletin, 19, 3-7.

Kagan, J. (1981). The Second Year-The emergence of SelfAwareness. Cambridge: Harvard University Press.

Long, E. R., Hammack, J. T., May, F. \& Campbell, B. J. (1958). Intermittent reinforcement of operant behavior in children. Journal of the Experimental Analysis of Behavior, 4(1), 315339.

McIlvane, W. J. (1992). Stimulus control analysis and nonverbal instructional methods for people with intellectual disabilities. Em N. Bray (Org.), International review of research in mental retardation, 18 (pp. 55-109). San Diego: Academic Press.

McIlvane, W. J. \& Stoddard, L. T. (1981). Acquisition of matchingto-sample performances in severe mental retardation:learning by exclusion. Journal of Mental Deficiency Research, 25, 33-48.

McIlvane, W. J., Dube, W. V., Kledaras, J. B., Iennaco, F. M. \& Stoddard, L. T. (1990). Teaching relational discrimination to individuals with mental retardation: some problems and some solutions. American Journal on Mental Retardation, 95(3), 283-296.

McIlvane, W. J., Serna, R. W., Dube, W. V. \& Stromer, R. (2000). Stimulus control topography coherence and stimulus equivalence: Reconciling test outcomes with theory. Em J. C. Leslie \& D. Blackman (Orgs.), Experimental and applied analysis of human behavior (pp. 85-110). Reno: Context Press.

O’Donnell, J. \& Saunders, K. J. (2003). Equivalence relations in individuals with language limitations and mental retardation. Journal of the Experimental Analysis of Behavior, 80, 131157.

Oliveira, T. P. (2003). Aprendizagem de pareamento de identidade por bebês. Dissertação de Mestrado, Universidade Federal de São Carlos, São Carlos.

Saunders, K. J. \& Spradlin, J. E. (1989). Condicional discrimination in mentally retarded adults: the effect of training the component simple discriminations. Journal of the Experimental Analysis of Behavior, 52,1-12. 
Simmons, M. W. \& Lipsitt, L. P. (1961). An operant-discrimination apparatus for infants. Journal of the Experimental Analysis of Behavior, 4, 233-235.

Wilkinson, K., M. \& McIlvane, W. J.(2001). Methods for studying symbolic behavior and category formation: Contributions of stimulus equivalence research. Developmental Review, $1-20$.
Weisberg, P. \& Rovee-Collier, C. (1998). Behavioral processes of infants and young children. Em A. Lattal \& M. Perone (Orgs.), Handbook of Research Methods in Human Operant Behavior (pp. 378-416). New York: Plenum Press.

Recebido em 30.06.2005

Primeira decisão editorial em 08.03.2006

Versão final em 25.04.2006

Aceito em 20.05.2006 